\title{
A study to assess the completeness of informed consent documents for biomedical research on human participants submitted to the institutional ethics committee of a tertiary care hospital
}

\author{
Nishanthi Anandabaskar ${ }^{1}$, Mourouguessine Vimal ${ }^{2} *$ Amol Rambhau Dongre ${ }^{3}$, \\ Rajendrakumar Nivaratirao Kagne ${ }^{4}$
}

\begin{abstract}
${ }^{1}$ Department of Pharmacology, ${ }^{2}$ Department of Pathology, ${ }^{3}$ Department of Community Medicine, ${ }^{4}$ Department of Forensic Medicine, Sri Manakula Vinayagar Medical College and Hospital, Puducherry, India
\end{abstract}

Received: 21 October 2019

Revised: 04 December 2019

Accepted: 05 December 2019

\section{*Correspondence:}

Dr. Mourouguessine Vimal,

Email: drvimalm@gmail.com

Copyright: @ the author(s), publisher and licensee Medip Academy. This is an open-access article distributed under the terms of the Creative Commons Attribution Non-Commercial License, which permits unrestricted non-commercial use, distribution, and reproduction in any medium, provided the original work is properly cited.

\begin{abstract}
Background: Informed consent is an essential pre-requisite for research on human participants. However, many studies have shown that informed consent documents (ICDs) are incomplete and lack many of the essential elements. The objective of the study was to assess the completeness of ICDs submitted to an institutional ethics committee (IEC) against the Indian Council of Medical Research (ICMR) ethical guidelines for biomedical research on human participants.

Methods: This is a retrospective cross-sectional study. The ICDs submitted to the IEC during the period from January 2015 to December 2017 were reviewed for completeness, with the help of a checklist which is based ICMR ethical guidelines for biomedical research on human participants 2006.

Results: A total of 212 ICDs were reviewed during the study period. More than $50 \%$ of the ICDs have clearly explained many of the essential elements like nature and purpose of the study $(62.3 \%)$, voluntary participation $(98.6 \%)$, procedures $(68.9 \%)$, risks $(71.2 \%)$, benefits $(92.9 \%)$, alternative treatments $(60.7 \%)$, maintaining confidentiality $(99.1 \%)$, no loss of benefits on withdrawal from the study $(87.8 \%)$ and contact details of principal investigator $(99.5 \%)$. However, the other essential elements of the ICD are either not mentioned or not clearly explained.

Conclusions: This study has shown that although majority of the ICDs submitted for review by the IEC have mentioned many of the essential elements, some of the elements like contact details of Chairman of IEC, future use of sample, compensation for trial related injury and provision of counseling for consent of genetics testing have not been stated.
\end{abstract}

Keywords: Informed consent form, Institutional review board, Participant information sheet, Research proposal

\section{INTRODUCTION}

Informed consent is an essential prerequisite for conduct of any research on human participants. It respects the autonomy of the participants and protects their freedom of choice. Informed consent is defined as "a continuous process, involving three main components - providing relevant information to potential participants, ensuring competence of the individual and the information is easily comprehended by the participants, and assuring voluntariness of participation". 1 The informed consent process encompasses a comprehensive discussion about 
the research study between the investigator and participant, and this process is documented by a signed informed consent document (ICD).

The ICD has two parts, namely the participant information sheet (PIS) and informed consent form (ICF). The PIS provides all necessary information about the study which is required for participants to make an informed choice on whether to participate in the study or not. The ICF is a document stating that the participant has understood the information provided in the PIS and is volunteering to participate in the research study. The ICDs and their vernacular translations are reviewed along with the research proposals by the institutional ethics committee (IEC) before granting approval for any research study. The Indian Council of Medical Research (ICMR) ethical guidelines for biomedical research on human participants have enlisted various essential elements that must be mentioned in the ICD, especially in the PIS. ${ }^{1,2}$

Previous literature has shown that the ICDs used for biomedical research on human participants are lacking vital information that are crucial for understanding the research study by the participants and are not in compliance with the standard guidelines and regulatory requirements. ${ }^{3-5}$ Providing inadequate information to the research participants is deceptive and unethical. Incomplete ICDs also reduce the speed of review of the research proposals by the ethics committee and increase their work burden. Thus, it is very important to ensure that the ICDs are complete and all the important information about the research proposal are mentioned in detail and in a language understandable to the participants.

In our college, structured research ethics training programs are being conducted for medical students and faculties. This study provided us a platform to assess the implementation of the knowledge and skills acquired during the training program by the investigators, while designing their ICDs for research. Also, our IEC was planning to undergo Strategic Initiative for Developing Capacity in Ethical Review (SIDCER) accreditation. Thus, as a part of the planning phase, we wanted to conduct an internal audit of the ICDs submitted to our ethics committee to strengthen and improve the existing IEC practices.

In view of the above, the present study was formulated to assess the completeness of ICDs submitted to our IEC against the ICMR ethical guidelines for biomedical research on human participants.

\section{METHODS}

\section{Study setting}

The present study was undertaken in the IEC of Sri Manakula Vinayagar Medical College and Hospital, Puducherry, India.

\section{Study design}

This is an internal audit of the ICDs submitted to the Institutional Human Ethics committee against the ICMR ethical guidelines for biomedical research on human participants. It was a cross-sectional study designed to evaluate the research ethics training program imparted to the medical students and faculties of our Institute.

\section{Framework for evaluation}

We used the Kirkpatrick's training evaluation framework for assessment of the effectiveness of these training programs. ${ }^{7}$ The Kirkpatrick four-level training evaluation model was created by Donald Kirkpatrick in 1959, the four-levels being "level 1: Reaction; level 2: Learning; level 3: Behaviour; and level 4: Results". We checked the level-3 of the Kirkpatrick's training evaluation framework on "behaviour" which assessed how well the investigators applied their research ethics training into their work of developing informed consent documents for their research. Majority of the studies evaluating training programs focused on level 1 and 2, and not many studies have assessed at level $3 .^{8-11}$

\section{Data source}

Secondary data was collected by studying the research proposals and ICDs submitted for the review of the institutional human ethics committee during the period from January 2015 to December 2017. The institutional research committee and ethics committee approval was obtained prior to initiation of the study. Consent waiver was obtained from the IEC. The identity of the researchers (whose research proposals were submitted for review to the IEC during the study period) was kept confidential.

\section{Data extraction}

Data collection tool: The completeness of these ICDs was assessed with the help of a predefined, structured checklist which was based on the standard guidelines for ICD preparation given by the ICMR ethical guidelines for biomedical research on human participants $2006 .^{2}$ The checklist consists of the essential elements that are required to be mentioned in the ICD (especially in the PIS) (Annexure 1).

Using the checklist, the presence or absence of the various essential elements in the PIS of the ICD was identified. For each of the elements, it was assessed whether it was mentioned or not. If mentioned, it was assessed if it was clearly explained or vaguely explained. Some elements in the checklist which were not applicable to certain studies were also noted. Also, any grammatical /spelling/typographical errors and use of medical jargons in the ICDs was assessed. The translations of the ICDs in vernacular language were also reviewed for any discrepancies with the English version. The assent forms 
and protocols of the research proposals were also reviewed. The year of submission of proposal to ethics committee, type of principal investigator (faculty/ postgraduate/undergraduate) and study design were also recorded.

The first two authors together assessed the completeness of the ICDs and consensus was reached by discussion. In case of any discrepancies between the first two authors, consultation was obtained from the third and fourth authors.

\section{Statistical analysis}

Data was entered in Microsoft Excel spreadsheet. Categorical data were summarized as frequency (percentage). Data analysis was done by Statistical Package for Social Sciences (SPSS) version 24.

\section{RESULTS}

The total number of research proposals submitted to the IEC, during the period from January 2015 to December 2017 was 247 , out of which consent waiver was granted for 26 proposals and ICD was missing in 9 proposals. Thus, a total of 212 ICDs and their study proposals were reviewed.
Table 1: Baseline characteristics of the research proposals submitted to the IEC $(n=212)$.

\begin{tabular}{|ll|}
\hline Characteristics & N $(\%)$ \\
\hline Type of principal investigator & \\
\hline Postgraduates & $150(70.8)$ \\
\hline Faculties & $38(17.9)$ \\
\hline Undergraduates & $22(10.4)$ \\
\hline PhD scholars & $2(0.9)$ \\
\hline Study design & \\
\hline Cross-sectional & $157(74)$ \\
\hline Interventional & $34(16)$ \\
\hline Mixed methods & $16(7.5)$ \\
\hline Cohort & $1(0.5)$ \\
\hline Case-control & $3(1.5)$ \\
\hline Qualitative & $1(0.5)$ \\
\hline
\end{tabular}

Out of the 212 proposals reviewed, 150 (70.8\%) had post graduate medical students as principal investigators, 38 (17.9\%) belonged to faculties, $22(10.4 \%)$ were submitted by undergraduate medical students and the remaining 2 $(0.9 \%)$ proposals by $\mathrm{PhD}$ scholars. Of them, 157 (74\%) were cross-sectional studies, 34 (16\%) were interventional, $16(7.5 \%)$ belonged to mixed methods, 3 $(1.5 \%)$ were case-control and one $(0.5 \%)$ each of cohort and qualitative studies (Table 1).

Table 2: Completeness of various elements of ICDs (applicable for all studies) submitted to the IEC (n=212).

\begin{tabular}{|llll|}
\hline Elements of ICD & Clearly explained & Vaguely explained & Not mentioned \\
\hline Statement that the study is a research & $\mathbf{N}(\boldsymbol{\%})$ & $\mathbf{N}(\boldsymbol{\%})$ & $\mathbf{N}(\boldsymbol{\%})$ \\
\hline Nature and purpose of the study & $2(0.9)$ & 0 & $210(99.1)$ \\
\hline Duration of participation & $132(62.3)$ & $80(37.7)$ & 0 \\
\hline Number of participants & $67(31.6)$ & $2(0.9)$ & $143(67.5)$ \\
\hline Procedures to be followed & $2(0.9)$ & $1(0.5)$ & $209(98.6)$ \\
\hline Foreseeable risks and discomforts & $146(68.9)$ & $66(31.1)$ & 0 \\
\hline Benefits & $151(71.2)$ & $47(22.2)$ & $14(6.6)$ \\
\hline Steps taken for ensuring confidentiality & $197(92.9)$ & $2(1)$ & $13(6.1)$ \\
\hline No loss of benefits on withdrawal from study & $210(99.1)$ & 0 & $2(0.9)$ \\
\hline Contact details of principal investigator & $186(87.8)$ & $2(0.9)$ & $24(11.3)$ \\
\hline Voluntary participation & $211(99.5)$ & 0 & $1(0.5)$ \\
\hline
\end{tabular}

Table 3: Completeness of additional elements of ICDs (applicable for selected studies) submitted to the IEC.

\begin{tabular}{|c|c|c|c|}
\hline \multirow{2}{*}{ Elements of ICDs } & Clearly explained & Vaguely explained & Not mentioned \\
\hline & $\mathbf{N}(\%)$ & $\mathbf{N}(\%)$ & $\mathbf{N}(\%)$ \\
\hline Investigations, if any $(n=136)$ & $62(45.6)$ & $69(50.7)$ & $5(3.7)$ \\
\hline $\begin{array}{l}\text { Availability of medical treatment for trial related } \\
\text { injuries or risk management }(n=28)\end{array}$ & $6(21.4)$ & $2(7.2)$ & $20(71.4)$ \\
\hline $\begin{array}{l}\text { Disclosure of alternative treatments if available } \\
(n=28)\end{array}$ & $17(60.7)$ & $2(7.1)$ & $9(32.2)$ \\
\hline $\begin{array}{l}\text { Storage period of biological sample and related data } \\
(n=76)\end{array}$ & $1(1.3)$ & 0 & $75(98.7)$ \\
\hline
\end{tabular}


As shown in Table 2, more than $75 \%$ of the ICDs have clearly explained many of the essential elements like voluntary participation (98.6\%), benefits of study $(92.9 \%)$, ensuring confidentiality $(99.1 \%)$, no loss of benefits on withdrawal from the study $(87.8 \%)$, and contact details of principal investigator containing the name, designation, department, affiliated institution, phone number and email ID (99.5\%). Also, 50\%-75\% of the ICDs have clearly explained the nature and purpose of the study $(62.3 \%)$, procedures to be followed in the study $(68.9 \%)$, foreseeable risks and discomforts (71.2\%) and alternative procedures/treatments if available $(60.7 \%)$. However, only $45.6 \%$ of the ICDs have clearly explained the investigations required to be performed in the study (Table 2 and 3). Unfortunately, majority of the ICDs have not mentioned certain essential elements like statement that it is research $(99.1 \%)$, the expected duration of participation $(67.5 \%)$, expected number of participants (98.6\%), availability of medical treatment for trial related injuries $(71.4 \%)$ and, storage period of biological sample and related data $(98.7 \%)$ (Table 2 and 3). Also, some of the elements were not mentioned in any of the ICDs reviewed (Annexure 2). None of the studies reviewed involved testing for HIV and none of them had the intent of commercialization since all the studies were academic studies and none of them were regulatory clinical trials.

Table 4: Analysis of other aspects of ICDs (applicable for selected studies) submitted to the IEC (n=212).

\begin{tabular}{|ll|}
\hline Aspects of ICDs & N (\%) \\
\hline Provided space for date, signature of investigator and witness in PIS & $201(94.8)$ \\
\hline Provided space for signature of participant in ICF & $212(100)$ \\
\hline Provided space for date and signature of the witness in ICF & $205(96.6)$ \\
\hline Presence of medical jargons in PIS & $120(56.6)$ \\
\hline Presence of grammatical/spelling/typographical errors in ICDs & $29(13.7)$ \\
\hline
\end{tabular}

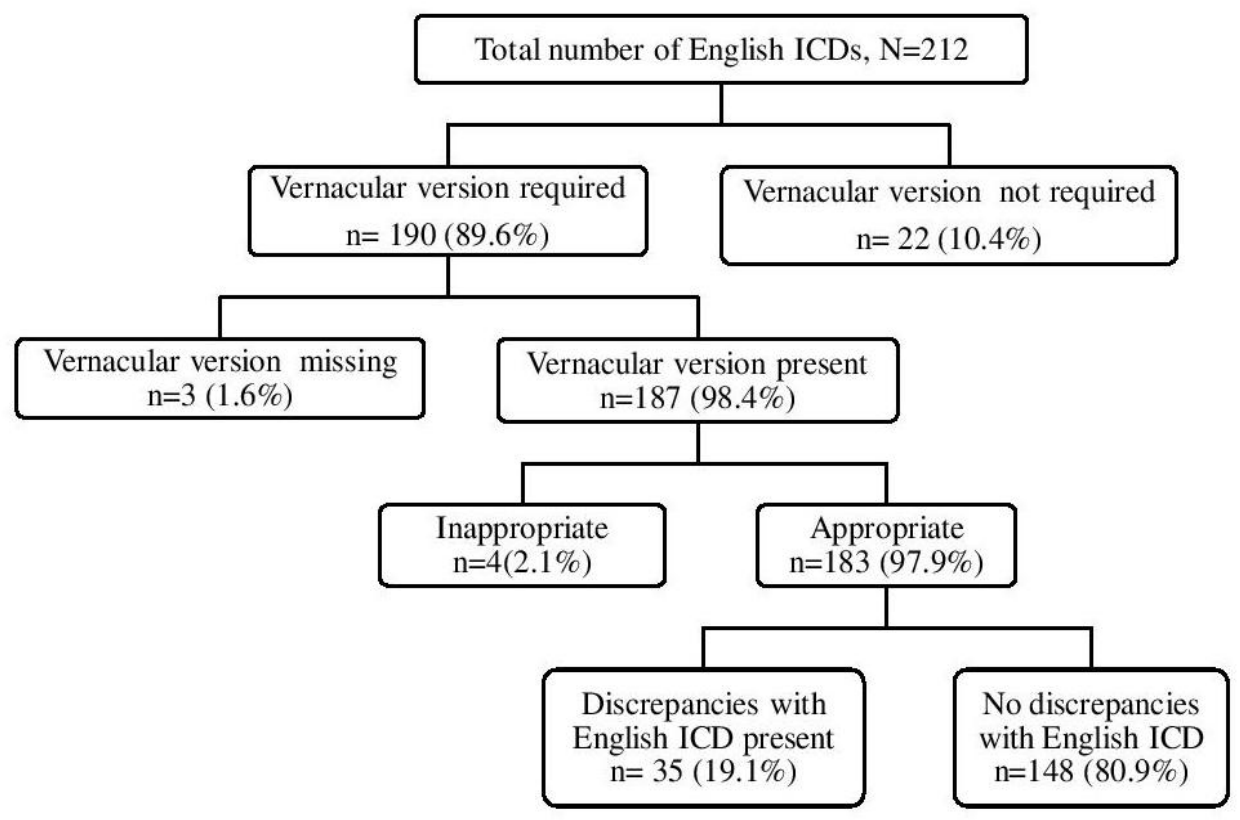

Figure 1: Analysis of the vernacular version of informed consent documents.

As shown in Table 4, of the 212 ICDs reviewed, majority of them $(n=201,94.8 \%)$ provided space for date, signature of investigator and witness in the PIS. Also, it was encouraging to find that all of them provided space for the signature of participant and $205(96.6 \%)$ provided space for date and signature of the witness in the ICF. It was seen that majority of the ICDs $(n=120,56.6 \%)$ reviewed had at least one medical jargon and 29 (13.7\%) ICDs had either grammatical errors, spelling mistakes or typographical errors.

\section{Analysis of the assent forms}

Among the 212 studies reviewed, 33 (15.6\%) studies required written assent from children and informed consent from their parents since these studies included children and adolescents in the age group of 12 to 18 years. Of the 33 studies which required written assent, only in $11(33.3 \%)$ studies, assent form has been attached. In all these studies, the ICDs attached were erroneously addressed to participants, instead of being addressed to parents. 


\section{Analysis of the vernacular version of ICDs and assent forms}

Of the 212 ICDs, vernacular version was required in 190 $(89.6 \%)$ consent forms, out of which in $3(1.6 \%)$ consent forms, vernacular version was missing. Hence, a total of $187(98.4 \%)$ vernacular consent forms were reviewed and $183(97.9 \%)$ of them were appropriate and $4(2.1 \%)$ consent forms were totally inappropriate. These inappropriate vernacular consent forms had contents which were totally irrelevant to the study. Also, the 183 vernacular consent forms which were appropriate had some discrepancies in 35 (19.1\%) forms (Figure 1). Also, out of the 187 vernacular ICDs reviewed, $109(58.3 \%)$ had either spelling or grammatical or typographical errors. Among the 11 English assent forms, only 3 (27.3\%) of them had vernacular forms attached to it. All of the 3 vernacular assent forms were appropriate and did not have any discrepancy with the English assent forms.

\section{DISCUSSION}

It is encouraging to find that more than half of the ICDs submitted for review by the EC have clearly explained many of the essential elements like nature and purpose of the study, voluntary nature of participation, procedures to be followed in the study, foreseeable risks and benefits, alternative treatments (if available), steps for ensuring confidentiality, no loss of benefits on withdrawal from the study, and contact details of principal investigator. On the contrary, more than half of the ICDs do lack certain essential elements like statement that it is research, duration of participation, number of participants, treatment of study related injury and storage period of biological samples and study related data. Moreover, none of the ICDs mentioned about contact details of Chairman of the EC, compensation, provision of counseling for genetic testing, and an offering of choice to participants regarding future use of their biological sample, refusal for storage and receipt of its results.

The results of this study are consistent with the findings of a similar study done in Sri Lanka by Abeysena et al, which showed that more than $75 \%$ of the ICDs informed about the purpose of the study, voluntary participation, potential benefits and maintenance of confidentiality, and only a few mentioned about the other essential elements. ${ }^{3}$

The optimistic finding that more than half of the ICDs clearly explained many of the essential elements shows the awareness of researchers about the importance of informed consent in research. This could be attributed to the periodic training of the investigators on bioethics and existence of a well-defined standard institutional template of ICD.

However, omission of certain essential elements in the ICD indicates the dimly recognized value of those elements in informed consent. Failure of mentioning certain essential elements in the ICD leads to difficulties in understanding the study and makes it ambiguous for the participant and can even lead to false perceptions and deception of the participants.

Majority of the researchers have failed to include the statement that, 'it is a research study', in the ICD. This could lead to an erroneous notion of therapeutic misconception among the participants. Therapeutic misconception is defined as a condition "when individuals do not understand that the defining purpose of clinical research is to produce generalizable knowledge, regardless of whether the subjects enrolled in the trial may potentially benefit from the intervention under study or from other aspects of the clinical trial". ${ }^{12}$ Many studies have shown that the prevalence of therapeutic misconception is high among research participants. ${ }^{13,14}$ Analysis of consent forms of Phase 1 gene transfer trials by Kimmelman et al, showed that the forms have been designed blurring the distinction between research and patient care. ${ }^{15}$ Thus, the ICMR ethical guidelines mandate the inclusion of the term "research", and word the PIS in an unambiguous manner to prevent this possibility of therapeutic misconception. ${ }^{2}$

Anticipated duration of participation with number of participants is critically important information for decision making on study participation, but have been left out in many ICDs. This finding was consistent with a similar study which found more than three fourth of the consent forms did not mention the duration of participation. ${ }^{3}$ Similarly, contact details of the chairman of the ethics committee, is required by participants for appeal against violation of their rights and it was missing in all the ICDs reviewed. Omission of these essential elements could be attributed to lack of knowledge among the researchers regarding their importance and failure to include them in the institutional ICD template.

The details on provision of free medical treatment and compensation for trial related injury were also missing in a multitude of ICDs. Similar results were found in two studies which assessed the completeness of project application forms submitted to IEC of a tertiary care hospital. ${ }^{4,5}$ This could be because in all these studies including the present study, the clinical trials reviewed were investigator-initiated academic research carried out by postgraduates as a part of their dissertation, and they would not be financially capable of providing compensation. Also, they could have been unaware of the regulatory requirements and significance of this provision. However, they should be discouraged from using this as a pretext to evade the provision of compensation. Also, they should be made to understand that as per the principle of beneficence and nonmaleficence, it is the right of the participant to receive free medical treatment and compensation in case of any harm due to their participation in research, and any infringement on this right is unethical. Although not clearly established in the 2006 ICMR guidelines, updated version published in 2017, clearly states that in any 
investigator-initiated studies, the investigator and/or the institution becomes the sponsor and they become accountable (onus is on them) for provision of free care and compensation. ${ }^{1}$ Thus, the investigators need to ensure that mechanisms are in place for budgetary provision of compensation like applying for funding grants from institution or other extramural sources like ICMR, Department of Science and Technology (DST), Department of Biotechnology (DBT) etc. before initiating a clinical trial.

Failure to inform the participants of the storage period of biological sample/data, and eliciting their choice regarding future use of their sample, refusal for storage and receipt of its results is evident from the fact that these elements were lacking in majority of the ICDs. This finding was consistent with a similar studies which found more than $90 \%$ of the ICDs have not commented on these aspects. $^{3,16}$ This practice stems from the lack of knowledge among the researchers that participants are the owners of their sample or data, and researchers and the institutions in which research is carried out are only custodians. ${ }^{1,2}$ Thus, the investigators should be educated that participants have the right to control and restrict the use of their samples/data and are entitled to receive the results of the study and also share the benefits of the research. However, many participants might be unaware of this right and it is the duty of the investigators to inform them.

The results of the present study will help us in improving the quality of the research ethics training programs conducted for our researchers by laying more emphasis on the aspects where they are ignorant. The results of the study will also aid in modifying our Institutional template of the ICDs and revision of the same in our IEC standard operating procedures. Thus, the study will help in improving our IEC practices and aid us in applying for SIDCER accreditation. ${ }^{6}$

However, the limitation of our study was that we assessed only the completeness of the ICDs and did not measure the other components that contribute to the quality of the informed consent process like analyzing the readability of the ICDs, evaluating the investigator-participant interaction, and assessment of participants' understanding of the ICD. Future research directed to explore these components of informed consent will aid in further strengthening this vital process, which forms the backbone for protection of research participants.

\section{CONCLUSION}

Thus, this study shows that although the majority of the ICDs submitted for review by the IEC have clearly explained many of the essential elements, some of them do lack certain elements. Thus, it is evident that there is an unmet need to further increase the knowledge and awareness among the researchers in preparation of ICDs. Periodic training program for researchers and ethics committee members in research ethics and good clinical practice is also mandatory. Formulation and periodic updating of a format/checklist of items to be present in the ICD will be helpful. Also, periodic internal audit/analysis of the ICDs submitted for review has to be done to identify the deficiencies/ lacunae and undertake corrective measures for the same.

\section{ACKNOWLEDGEMENTS}

This project was submitted for fulfillment of the course requirements for the degree 'Post Graduate Diploma in Bioethics' by Dr. Nishanthi Anandabaskar, to the Bharathiyar University in the year 2018. The authors are very thankful to Dr Vasantha Muthuswamy, Dr. Nandini K. Kumar, Dr. Sudha Ramalingam, Dr. Nabeel MK, Dr. Kavitha Subramanian and all the other faculty members of Postgraduate Diploma in Bioethics (PGDBE) course for their valuable guidance. The authors would like to thank the administrators of Sri Manakula Vinayagar Medical College and Hospital for their support.

\section{Funding: No funding sources}

Conflict of interest: None declared

Ethical approval: The study was approved by the Institutional Ethics Committee of Sri Manakula Vinayagar Medical College and Hospital, Puducherry, India

\section{REFERENCES}

1. Indian Council of Medical Research. National Ethical Guidelines for Biomedical and Health Research Involving Human Participants. New Delhi: ICMR; 2017. Available at: https://www.icmr.nic.in/sites/ default/files/guidelines/ICMR_Ethical_Guidelines_2 017.pdf. Accessed on 4 June 2019.

2. Indian Council of Medical Research. Ethical guidelines for biomedical research on human participants. New Delhi: ICMR; 2006. Available at: https://www.icmr.nic.in/sites/ default/files/guidelines/ethical_guidelines_0.pdf. Accessed on 4 June 2019.

3. Abeysena C, Jayamanna K, Dep S. Completeness of consent forms in research proposals submitted to an ethics review committee. Indian $\mathrm{J}$ Med Ethics. 2012;9:100-3.

4. Shetty YC, Marathe PA, Billa GV, Nambiar CPN.A study to assess completeness of project application forms submitted to Institutional Ethics Committees (IEC) of a tertiary care hospital. Perspect Clin Res. 2012;3:133-8.

5. Shah PC, Panchasara AK, Barvaliya MJ, Tripathi CB. A Study of Assessing Errors and Completeness of Research Application Forms Submitted to Institutional Ethics Committee (IEC) of a Tertiary Care Hospital. J Clin Diagn Res. 2016;10:10-2.

6. Forum for ethical review committees in the Asian and Western Pacific region (FERCAP). SIDCER Recognition Programme. Available at: 
http://www.fercap-sidcer.org/recog.php. Accessed on 4 June 2019.

7. Rouse DN. Employing Kirkpatrick's evaluation framework to determine the effectiveness of health information management courses and programs. Perspect Health Inf Manag. 2011;8:1.

8. Ajuwon AJ, Kass N. Outcome of a research ethics training workshop among clinicians and scientists in a Nigerian university. BMC Med Ethics. 2008;9:1.

9. Trigotra S, Jaiswal S, Mittal A, Bhardwaj A. Impact of a Publication Ethics Orientation Program on the Knowledge and Attitude of Postgraduate Students of Health Sciences. J Clin Diag Res. 2019;13(2):4-9.

10. Asghari F, Samadi A, Dormohammadi $T$. Effectiveness of the course of medical ethics for undergraduate medical students. J Med Ethics Hist Med. 2009;2:7.

11. Maddineshat M, Yousefzadeh MR, Mohseni M, Maghsoudi Z, Ghaffari ME. Teaching ethics using games: Impact on Iranian nursing students' moral sensitivity. Indian J Med Ethics. 2018;14:1-6.

12. Henderson GE, Churchill LR, Davis AM, Easter MM., Grady C, Joffe S, et al. Clinical trials and medical care: defining the therapeutic misconception. PLoS Med. 2007;4(11):324.

13. Mansour H, Zaki N, Abdelhai R, Sabry N, Silverman $\mathrm{H}$, El-Kamary SS. Investigating the informed consent process, therapeutic misconception and motivations of Egyptian research participants: a qualitative pilot study. East Mediterr Health J. 2015;21(3):155-63.

14. Christopher PP, Stein MD, Springer SA, Rich JD, Johnson JE, Lidz CW. An exploratory study of therapeutic misconception among incarcerated clinical trial participants. AJOB Empir Bioeth. 2015;7(1):24-30.

15. Kimmelman J, Levenstadt A. Elements of style: consent form language and the therapeutic misconception in phase 1 gene transfer trials. Human Gene Therapy. 2005;16(4):502-8.

16. Fernandez CV, Kodish E, Taweel S, Shurin S, Weijer C. Disclosure of the Right of Research Participants to Receive Research Results. An Analysis of Consent Forms in the Children's Oncology Group. Cancer. 2003;97:2904-9.

Cite this article as: Anandabaskar N, Vimal M, Dongre AR, Kagne RN. A study to assess the completeness of informed consent documents for biomedical research on human participants submitted to the institutional ethics committee of a tertiary care hospital. Int J Basic Clin Pharmacol 2020;9:138-45. 


\section{ANNEXURES}

Annexure 1: Checklist of the essential elements that are required to be mentioned in the ICDs.

- Statement that the study is a research.

- $\quad$ Nature and purpose of the study.

- $\quad$ Expected duration of participation.

- $\quad$ Expected number of participants.

- $\quad$ Procedures to be followed in the study.

- Investigations, if any, to be performed.

- $\quad$ Foreseeable risks and discomforts adequately described.

- $\quad$ Benefits to participant, community or medical profession as may be applicable

- $\quad$ Policy on compensation for trial related injury.

- Availability of medical treatment for trial related injuries or risk management.

- Disclosure of alternative procedures/treatments if available.

- $\quad$ Steps taken for ensuring confidentiality.

- No loss of benefits on withdrawal from the study.

- Benefit sharing in the event of commercialization.

- Contact details of Principal Investigator (containing the name, designation, department, affiliated institution, phone number and email ID) for asking more information related to the research or in case of injury.

- Contact details of Chairman of the IEC for appeal against violation of rights.

- Voluntary participation.

- If test for genetics and HIV is to be done, counseling for consent for testing must be given as per national guidelines.

- $\quad$ Storage period of biological sample and related data.

- $\quad$ Choice offered to participant regarding future use of sample, refusal for storage and receipt of its results.

Annexure 2: Elements not mentioned in any of the ICDs.

- $\quad$ Contact details of Chairman of Ethics Committee $(n=212)$.

- $\quad$ Choice offered to participant regarding future use of sample, refusal for storage and receipt of its results $(n=76)$.

- $\quad$ Policy on compensation for trial related injury $(n=28)$.

- If test for genetics is to be done, counseling for consent for testing $(n=2)$. 